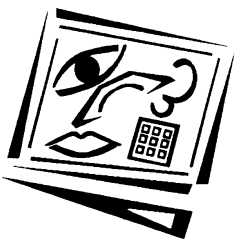

\title{
Faculty's acceptance of computer based technology: Cross-validation of an extended model
}

\author{
Tunku Badariah Tunku Ahmad, Kamal Basha Madarsha, Ahmad Marzuki \\ Zainuddin, Nik Ahmad Hisham Ismail and Mohamad Sahari Nordin \\ International Islamic University Malaysia
}

\begin{abstract}
The first aim of the present study is to validate an extended technology acceptance model (TAME) on the data derived from the faculty members of a university in an ongoing, computer mediated work setting. The study extended the original TAM model by including an intrinsic motivation component - computer self efficacy. In so doing, the study assessed the direct and indirect effects of computer self efficacy on the use of the technology, via the perceived usefulness and intention to use the technology voluntarily. The second purpose of the study is to evaluate gender and age invariants of the causal structure of TAME. This cross-validation procedure determined whether gender and age group moderated the causal structure of the model, and thus the generality of TAME. The data were collected from a self reported questionnaire administered to 731 faculty members of a public university in Malaysia. The results of structural equation modeling supported the adequacy of TAME. Although the TAME's causal structure was applicable to both male and female staff, age group appeared to moderate the structural relationships among the constructs of interest.
\end{abstract}

\section{Introduction}

The Technology Acceptance Model or TAM (Davis, Bagozzi \& Warshaw, 1989) is one of the most profound frameworks frequently used in studies to predict and explain the use of computer based applications and solutions. The model asserts that the adoption of a technology is determined by the user's intention to use, which in turn is influenced by his or her attitudes towards the technology. It is very likely that the variability in these attitudinal and behavioral constructs depends on the user's perceptions - perceived usefulness (PU) and perceived ease of use (PEU). While PU indicates the extent to which the use of the technology is promising to advance one's work, PEU represents the degree to which the technology seems to be free of effort (Davis et al., 1989). This model posits that attitudes and behavioral intention mediate the effects of PU and PEU, the two constructs of extrinsic motivation.

Theories and models which attempt to predict and explain the acceptance and adoption of computer-based technology abound. For example, Rogers' Diffusion of innovations theory (Rogers, 2003; Straub, 2009) explains technology adoption as a process taking place over time and is dependent on factors such as attributes of the technology, nature of the social system in which the technology is to be adopted, role of change agents and opinion leaders, and adopter categories. Another theoretical base, the Concerns Based Adoption Model or CBAM (Hall, 1979), frames technology 
adoption in terms of how the technology is able to address the concerns or needs of the adopting unit. The model proposes seven stages of concern (awareness, informational, personal, management, consequence, collaboration and refocusing) that the adopting unit experiences before finally deciding to adopt. While Rogers' diffusion theory and CBAM are helpful in understanding certain technology adoptions, they are too broad and rather complex to address the concerns of the present study. In light of these broad and complex theories, TAM appears to be simple yet reasonable and robust (Venkatesh \& Davis, 2000). Thus the study on TAM has been receiving continual interest from decision makers, practitioners and researchers. Through the years, research on the efficacy of TAM has covered a broad range of settings, samples, and computing technology across knowledge domains. However, recent meta-analyses (Ma \& Liu, 2004; Schepers \& Wetzels, 2007; Yousafzai, Foxall \& Pallister 2007) suggest that our understanding of technology adoption and of TAM could further be enhanced if several overriding issues are addressed.

The first of these issues concerns the criterion measures used in previous TAM studies, primarily that the (i) behavioural intention to use, and (ii) use of technology were based on the adoption of specific applications. In educational settings, individual studies used either the adoption of word processors (Davis, et al., 1989), spreadsheets (Mathieson, 1991), PowerPoint (Hu, Clark \& Ma, 2003), email (Shih, 2004), multimedia learning systems (Saade, Nebebe \& Tan, 2007), e-learning (Ndubisi, 2006), digital library (Hong, Wong, \& Tam, 2002), or learning management system (Yi \& Hwang, 2003). Ma and Liu (2004) observe that the "differences in measurement items between studies tend to be the result of adapting TAM to different technologies" (pp. 61-62). Clearly, such measures constitute a piecemeal approach to the understanding of technology acceptance, and are insufficient to represent the complexity of a technology-based work environment. In daily work, a faculty member uses a plethora of communication systems, office systems, and general computer-based applications. It is reasonable, therefore, to extend and validate the adequacy of the TAM in an ecologically sound setting, where all sorts of computer-mediated systems and applications are used by faculty members.

The second issue in the TAM literature concerns the generality of the model across user populations. The literature indicates that more than $40 \%$ of the research on TAM (Schepers \& Wetzels, 2007; Yousafzai, Foxall \& Pallister 2007) used students as the sample. However, results yielded from student samples are not replicable to other types of users within education communities. In fact, Schepers and Wetzels found that the user-type moderated the causal relationships within the model; on the average, student samples produced reliably superior effect sizes than did the non-student samples. Furthermore, Selwyn (2007) claims that, "the formal use of computer technology [by faculty and administrators] in many areas of higher education could best be described as sporadic, uneven, and often low level" (p.84, emphasis added). It is very likely that each student sample consists of relatively homogenous users who are required, and in many cases willing, to try out new technology. Additionally students, being younger and more exposed to current and emerging technologies, are more inclined to adopting technologies in their lives. Faculty members, on the other hand, are more diverse and more experienced, but are less inclined to adopt new technology unless it is imposed on them, hence the divide between digital immigrants (older but comfortable users of computer technology) and digital natives (young and technologically savvy users). The study by Kennedy, Dalgarno, Bennet, Judd, Gray and Chang (2008) documents some differences in the use of various types of digital 
technology by students (digital natives) and staff (digital immigrants), although it concludes that the differences are minimal and insubstantial.

Third, although TAM is one of the most influential bases to describe technology acceptance, the empirical evidence gleaned from various TAM studies yielded mixed signals. Inconsistent results abound, both in terms of the magnitude and direction of the relationships (e.g., Dasgupta, Granger \& McGarry, 2002; Teo, 2008) among the constructs of TAM; others pointed to unreliable relationships (Lowry, 2002; Shih, 2004). One possible reason for these discrepancies is the existence of moderating variables influencing technology acceptance inconsistently across the levels of the independent variables. Unfortunately, studying the interactive effects of a third variable is a neglected area in TAM research. In the limited number of cross-validation research studies on technology acceptance, there are indications that age (Kennedy et al., 2008; Sam, Othman, \& Nordin, 2005) gender (Gefen \& Straub, 2000; Kennedy et al., 2008), and culture (Straub, Keil, \& Brenner, 1997) moderated the expected causal relationships. Besides gender and culture, Yousafzai, Foxall and Pallister (2007) postulate that differences in subject type, method type, technology type, and measurement of usage characteristics are likely to moderate the hypothesised relationships.

Against this background, one purpose of the present study was to validate an extended technology acceptance model (TAME) on the data derived from the faculty members of a university in an ongoing, computer-mediated work setting. The study extended the original TAM model by including an intrinsic motivation component computer self efficacy. In so doing, the study assessed the direct and indirect effects of computer self efficacy on the use of the technology, via the perceived usefulness and intention to use the technology voluntarily. The second purpose of the study was to evaluate gender and age-invariant of the causal structure of TAME. This crossvalidation procedure determined whether gender and age group moderated the causal structure of the model, and thus the generality of TAME.

\section{The Extended Technology Acceptance Model}

Framed within Ajzen and Fishbein's (1980) theory of reasoned action (TRA), Davis et al., (1989) proposed a robust yet simple model of technology acceptance (TAM) that would "explain computer usage behavior" (p. 983). The TAM (Figure 1) is a powerful framework because it provides theoretically valid reasons for the variability in one's acceptance and use of computer technology.

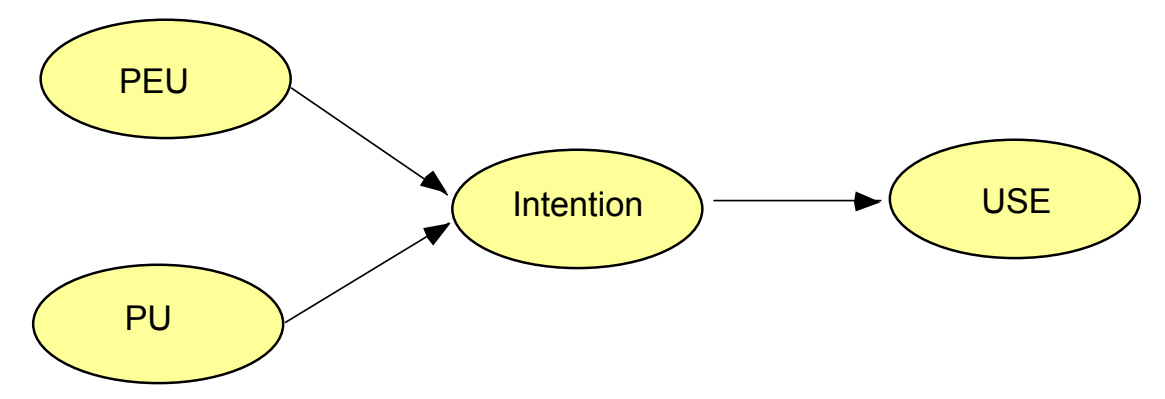

Figure 1: Technology Acceptance Model (Davis, et al., 1989) 
The model is parsimonious in the sense that it is based simply on three antecedent variables - PU, PEU, and behavioural intention - to predict use, albeit PEU has been found to be less influential and reliable (Ma \& Liu, 2004). Nevertheless, both PU and PEU were the factors that extrinsically motivate users to accept, adopt and use the technology (Igbaria, Iivari, \& Maragahh, 1995).

The inclusion of an intrinsic motivation construct, most importantly the self efficacy beliefs, would definitely provide deeper and richer understanding of why and how the technology is used (Figure 2). Bandura (1977) argues that one's sense of efficacy is one's causal judgment in predicting one's ability to perform a behavior successfully. In relation to computer usage (Straub, 2009), the belief that one can even communicate electronically with students, for example, reflects a high level of efficacy. An efficacious faculty, in essence, believes that he or she can assess the usefulness of the computer-mediated work environment, thus bringing out positive changes in his or her behavioral intention and use of the technology. More importantly, faculty's computer self efficacy is determined by past experience, observing others, social persuasion, and affective arousal. Therefore one's computer self efficacy, being changeable in nature, could be enhanced through intervention, which may include specifically designed training (Kimmel \& Kilbridge, 1991; Sahari, 2001).

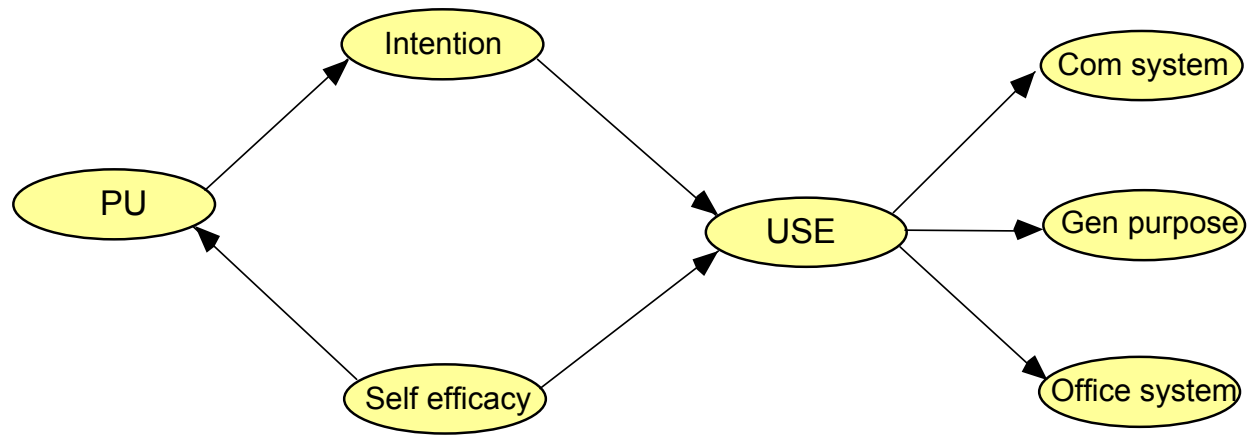

Figure 2: The Extended Technology Acceptance Model (TAME)

Social cognitive theory asserts that as a variable, self efficacy strongly affects a person's decision to attempt a task, the amount of effort put in and the degree of persistence exhibited in completing the task, and the ability to withstand difficult circumstances (Salomon, 1984). An efficacious faculty has higher levels of comfort and confidence to attempt computer mediated tasks, which may vary from something as simple as using computer applications to enhance research and teaching to something as complex as developing a web based learning environment. Efficacious users are committed to accomplishing challenging tasks involving the use of the technology simply because they find it intrinsically rewarding (Deci, 1975; Deng, Doll \& Truong, 2004). In fact, Birch and Burnett (2009) found that with pioneers and early adopters of e-learning environments, intrinsic rewards were more a driving force for technology uptake than extrinsic rewards. Based upon these arguments, it is hypothesised that:

Hypothesis 1: Computer self efficacy directly influences faculty's use of the computer mediated technology. 
The literature suggests that computer self efficacy accounts for substantial variance in an individual's beliefs (Igbaria \& Iivari, 1995, Kwon, Choi \& Kim, 2007) and behaviour (Compeau \& Higgins, 1995) in using computer based technology. Since an efficacious faculty has confidence and positive judgment in using computers, it is reasonable to argue that the faculty could anticipate and appreciate the usefulness of computer mediated technology, which in turn would determine their adoption of the technology. One's positive judgment about one's ability to use computer based technology would facilitate one's perceptions towards the usefulness of computer technology in broader range of tasks. Thus, computer self efficacy also indirectly affects technology acceptance via the beliefs a person holds about the usefulness of the technology. Consistently, several previous studies had supported the mediated effects of computer self efficacy (Doll, \& Truong, 2004; Deng et al., 2004; Igbaria \& Iivari, 1995). Therefore in this study, it is hypothesised that:

Hypothesis 2: Computer self efficacy indirectly influences faculty's use of the computer mediated technology through perceived usefulness and intention to use.

Perceived usefulness is one's belief that a given technology will help one to achieve one's work goals. With respect to faculty's use of computers, it represents the degree to which the user perceives the technology would facilitate his or her performance. Data from previous studies supported the expectation that perceived usefulness influences one's intention to use, which ultimately determines the use of computer based technology. In the current study, it is hypothesised that:

Hypothesis 3: Perceived usefulness positively influences intention to use the computer mediated technology.

Hypothesis 4: Intention to use computer mediated technology positively influences its use.

\section{Method}

The data for this study were obtained from 731 faculty members of a public university in Malaysia, representing almost $50 \%$ of the population of academic staff. A majority of the sample were females $(60 \%) ; 53 \%$ aged 40 years or below. The respondents, who consisted of professors and lecturers of 23 different nationalities, were teaching in 10 faculties in various academic disciplines. The sample size was deemed adequate for the application of structural equation modeling (SEM) to address the research objectives.

To collect the data, we used a self-reported questionnaire containing items that measured three exogenous constructs of interest, namely computer self efficacy, perceived usefulness (PU), and intention to use. In addition, the frequency of using three types of computer mediated systems - communication systems, general purpose systems and office systems - collectively served as the endogenous variable (USE). Each construct consists of items to which respondents would indicate on a 5point scale the extent of their agreement or disagreement with each assertion. Table 1 lists the constructs, items, and internal consistency indexes used in the study.

The study applied a three-stage structural equation modeling, using the AMOS (version 16) model-fitting program to test the research hypotheses. The study first assessed the validity of the measurement model, the confirmatory factor analysis of the 
use of computer mediated technology. Next, we examined the good-fit of the fullfledged TAME (Figure 3). Finally, we cross-validated the model to assess the moderating effects of gender and age groups of TAME. The hypothesised models were estimated using the covariance matrix derived from the data; thus, the estimation procedure satisfied the underlying statistical distribution theory, and yielding estimates of desirable properties. The study adopted maximum likelihood estimation in generating estimates of the full-fledged model. Once a model was estimated, we applied a set of conventionally accepted criteria to evaluate its goodness of fit. The measures, based on the conventionally accepted criteria for deciding what constitutes a good fit model, assess the (1) consistency of the hypothesised model with the empirical data, (2) reasonableness of the estimates, and (3) the proportion of variance of the dependent variables accounted for by the exogenous variables.

Table 1: Measurement of the variables of the hypothesised model

\begin{tabular}{|c|c|c|c|c|c|}
\hline Construct & Item & Measure & Mean & SD & Alpha \\
\hline \multirow[t]{3}{*}{$\begin{array}{l}\text { Computer } \\
\text { self efficacy }\end{array}$} & se1 & $\begin{array}{l}\text { I have the skills required to use computer } \\
\text { applications for presenting lectures }\end{array}$ & 3.81 & .88 & \multirow[t]{3}{*}{.8988} \\
\hline & se2 & $\begin{array}{l}\text { I have the skills and knowledge required to use } \\
\text { computer applications for demonstrating specific } \\
\text { concepts in class }\end{array}$ & 3.63 & .99 & \\
\hline & se3 & $\begin{array}{l}\text { I have the skills required to communicate } \\
\text { electronically with my students }\end{array}$ & 3.60 & 1.03 & \\
\hline \multirow[t]{3}{*}{$\begin{array}{l}\text { Perceived } \\
\text { usefulness }\end{array}$} & pu1 & $\begin{array}{l}\text { I believe that the use of technology in the class- } \\
\text { room enhances student learning in my discipline }\end{array}$ & 4.17 & .81 & \multirow[t]{3}{*}{.8577} \\
\hline & pu2 & $\begin{array}{l}\text { I believe that email, listservs, and other forms of } \\
\text { electronic communication are important tools in } \\
\text { faculty/ student communication }\end{array}$ & 4.18 & .83 & \\
\hline & pu3 & $\begin{array}{l}\text { I believe that web-based instructional materials } \\
\text { enhance student learning }\end{array}$ & 3.98 & .819 & \\
\hline \multirow[t]{2}{*}{$\begin{array}{l}\text { Behavioral } \\
\text { intention }\end{array}$} & int1 & $\begin{array}{l}\text { I will use computer applications to present lecture } \\
\text { materials in class }\end{array}$ & 4.05 & .84 & \multirow[t]{2}{*}{.5166} \\
\hline & int2 & $\begin{array}{l}\text { I will teach a course that will be delivered totally } \\
\text { on the world wide web }\end{array}$ & 3.36 & .99 & \\
\hline \multirow{3}{*}{$\begin{array}{l}\text { Use of comm- } \\
\text { unication } \\
\text { systems }\end{array}$} & com1 & Frequency of using email & 4.61 & .58 & \multirow[t]{3}{*}{.8143} \\
\hline & com2 & Frequency of using web browser & 4.41 & .79 & \\
\hline & com3 & Frequency of using search engine & 4.40 & .80 & \\
\hline \multirow{3}{*}{$\begin{array}{l}\text { Use of gen- } \\
\text { eral purpose } \\
\text { systems }\end{array}$} & gp1 & Frequency of using document editing/composing & 3.78 & 1.06 & \multirow[t]{3}{*}{.8213} \\
\hline & $\mathrm{gp} 2$ & Frequency of using file transfer & 3.85 & 1.01 & \\
\hline & gp3 & Frequency of using information seeking & 4.07 & .97 & \\
\hline \multirow{3}{*}{$\begin{array}{l}\text { Use of office } \\
\text { systems }\end{array}$} & app1 & Frequency of using spreadsheet & 3.41 & 1.29 & \multirow[t]{3}{*}{.6801} \\
\hline & app2 & Frequency of using graphics & 2.90 & 1.29 & \\
\hline & app3 & Frequency of using document processing (PDF) & 3.44 & 120 & \\
\hline
\end{tabular}

\section{Results}

This section presents the results of the structural equation modeling that addressed the objectives of the study.

\section{Validity of the measure of use of computer mediated technology}

Figure 2 contains the measurement model of the faculty's use of computer mediated technology that comprised three first-order and one second-order factors. Each of these first-order factors was measured by three items; each item was assumed to load 
only on its respective dimension. The three factors, namely the communication systems, general purpose systems, and office systems were expected to load on the second-order factor, the staff members' use of the technology (USE). Using the maximum likelihood estimation procedure of the confirmatory factor analysis, the validity of this measurement model was tested first.

The results indicated that the hypothesised nine-item measurement model was consistent with the data. The overall fit of the model was adequate, the relative Chisquare $=3.6 ;$ RMSEA $=.06 ; \mathrm{CFI}=.97 ; \mathrm{TLI}=.96$. In other words, the measurement of technology use did generate the observed covariance matrix; there was no evidence that the measurement model is incorrect. In addition, the direction and magnitude of factor loadings were substantial and statistically significant, and the model was free from offending estimates. The Cronbach's alpha for the first-order factors were .81 (communication systems), .82 (general purpose systems), and .68 (office systems). The data also supported the measurement adequacy in terms of their convergent and divergent validity; these are supporting evidence for construct validity of the model.

\section{Adequacy of the causal structure of the extended model (TAME)}

Figure 3 summarises the results of structural equation modeling of TAME. The confirmatory modeling yielded consistency of the hypothesised causal relationships with the data (relative Chi-square $=3.7$; RMSEA = .06; CFI = .95; TLI = .94). All these fit indices satisfied their critical cutscores; the results, therefore, indicated a fitting TAME.

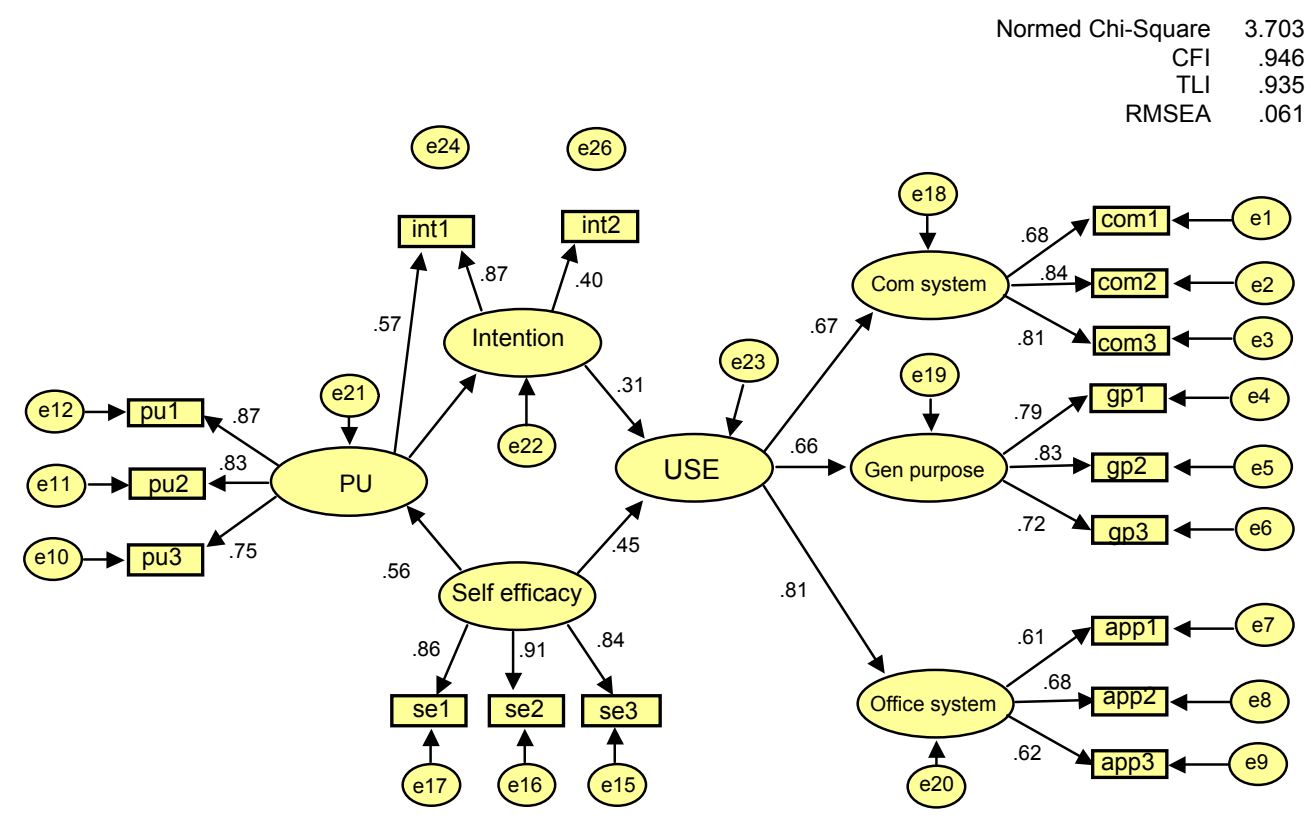

Figure 3: Standardised coefficients of the hypothesised TAME

The parameter estimates of the hypothesised model were free from offending values. All path coefficients of the casual structure were statistically significant at .005 levels, and were of practical importance, since the smallest value of the standardised path coefficient was 0.31 . The data indicated that computer self efficacy was relatively more 
influential than did the behavioural intention in affecting the faculty's use of computer technology. The total standardised effect size of computer self efficacy $\rightarrow$ use was .55, .10 indirectly via PU and intention to use. In addition, the analysis revealed that collectively the three exogenous variables explained almost $40 \%$ of the variability of the faculty's technology use. In sum, the results provided support for the four research hypotheses.

\section{Gender and age-invariant of the extended model}

Another objective of this study was to examine the structural invariance of TAME across two likely moderators, gender and age groups. To test gender-invariant, a simultaneous analysis on both the male $(\mathrm{n} 1=440)$ and female $(\mathrm{n} 2=291)$ samples was conducted, first without constraining the structural paths; the results derived a baseline Chi-square value. Next, the structural paths (self efficacy $\rightarrow$ USE; self efficacy $\rightarrow$ PU; PU $\rightarrow$ intention; intention $\rightarrow$ USE) were constrained to be equal for the male and female groups. The analysis of this constrained TAME produced another Chi-square value, which was then tested against the baseline value for statistically significant differences. A similar procedure was used to examine the age-invariant of TAME. The results of the multiple-group SEMs are presented in Table 2.

The invariance test across the male and female groups resulted in a statistically insignificant change in the Chi-square value, Chi-square $(\mathrm{df}=4)=13.44, \mathrm{p}>.005$. Simply said, the difference in the Chi-square values between the unrestricted model and the constrained model did not produce a poorer fit model. The path coefficients did not vary significantly across gender. It is justifiable then to conclude that gender did not interact with the exogenous variables to influence the staff members' use of computer mediated technology; hence, gender is not a moderating variable.

Table 2: Results of the multiple group modeling

\begin{tabular}{|l|l|c|c|c|c|}
\hline \multicolumn{2}{|c|}{} & Chi squared & $\mathrm{df}$ & Critical-value & $\begin{array}{c}\text { Chi squared } \\
\text { change }\end{array}$ \\
\cline { 1 - 4 } Gender & Unrestricted & 525.56 & 224 & 4.9 & 13.44 \\
\cline { 2 - 4 } & Constrained & 539.00 & 228 & & $20.59^{*}$ \\
\cline { 1 - 4 } Age & Unrestricted & 571.43 & 224 & 14.9 & \\
\cline { 2 - 4 } & Constrained & 592.02 & 228 & & \\
\hline
\end{tabular}

* Statistically significant at .005

On the contrary, the age-invariant test was statistically significant, Chi-square $(\mathrm{df}=4)$ $=20.59, \mathrm{p}<.005$. Specifically, the constrained TAME was much worse than the unrestricted model. This shows that the path coefficients varied across the two levels of age group (40 years old or less; more than 40 years old) because age group interacted significantly with the exogenous variables. Thus, group memberships moderated the causal relationships.

\section{Discussion and conclusion}

The findings of the present study have expanded the existing body of knowledge on TAM in several ways. First, the results substantiated the psychometric adequacy of the measure of use of computer mediated technology. The measure seems sufficient to represent the ongoing use of communication systems, office systems, and general computer based applications among faculty members. 
Second, the results validated the good fit of the extended technology acceptance model (TAME). The results also supported the efficacy of the original TAM (Davis et al., 1989), which posits that perceived usefulness and behavioral intention explain computer usage. In addition, the results are congruent with the results of earlier studies on computer self efficacy (Compeau \& Higgins, 1995; Dabholkar \& Bogazzi, 2002; Ellen, Bearden \& Sharma, 1991) which found the influential effect of computer self efficacy on technology acceptance. The pattern discovered was that when faculty understand the usefulness of computer utilisation, they are more likely to use the tool. More importantly, the present study found that faculty's acceptance of technology does not depend only on extrinsic motivation - perceived usefulness of the technology - but also on their confidence in their own ability to use it. The data indicated that computer self efficacy was relatively more influential than behavioural intention in affecting the use of computer technology.

Third, while the present study provides indications that the extended model explains the use of computer technology among male and female users, an age factor appears to limit the generalisability of the TAME. This means that in an environment where faculty members volunteer and/or are required to use the computer to facilitate teaching and learning, gender does not affect faculty's use of technology. This finding is consistent with Sam, Othman and Nordin (2005) who found no significant differences between the sexes with respect to interest in adopting technology, actual use of technology and the skills levels involved in the technology use. This suggests that the gender gap in technology uptake among male and female users is slowly diminishing.

However, the latter finding pertaining to the effect of age is consistent with results of the work by Venkatesh, Morris, Davis and Davis (2003), where older users - the digital immigrants - were found to have more trouble accepting technology. They also pointed out that younger users place more importance on the extrinsic rewards of technology uptake as compared to their older counterparts. This finding contradicts the more recent discovery by Kennedy et al., (2008) that the divide between younger and older digital technology users is small and negligible, suggesting that it might be a real factor impeding technology adoption among older users. The gap in the computer use among immigrants and natives possibly occurs at the age of 40; this postulation calls for further studies to identify more accurately the threshold of the digital gap. Contrary to what Teo (2008) had found - that no significant relationship exists between age and computer attitudes - the present study uncovered statistically significant effects of age on the structural relationships, possibly due to its employment of a more heterogeneous sample in terms of age composition. Teo (2008), on the other hand, had used a student sample that was highly homogenous in nature, which could have been a factor leading to the insignificant effects of age on computer attitudes.

The findings of the study have some practical implications and some involving pedagogical aspects. First, since one's self efficacy is changeable, a university management may consider creating intervention programs or in house training to increase computer self efficacy among older faculty members. Second, these older faculty members are less efficacious and less comfortable with digital technology, and may need to see a concrete example or model of how they can integrate computers into their teaching. Third, they should be given an appropriate platform where they can share the concerns and experiences in using computer technology. Finally, institutional 
support from the university management in terms of incentives and infrastructure is a crucial element that will influence faculty members to adopt new technology in their teaching.

\section{References}

Bandura, A. (1977). Self-efficacy: Toward a unifying theory of behavioral change. Psychological Review, 84, 191-215.

Birch, D. \& Burnett, B. (2009). Bringing academics on board: Encouraging institution-wide diffusion of e-learning environments. Australasian Journal of Educational Technology, 25(1), 117134. http:/ / www.ascilite.org.au/ajet/ ajet25/birch.html

Compeau, D. R. \& Higgins, C. A. (1995). Computer self-efficacy: Development of a measure and initial test. MIS Quarterly, 19, 189-211.

Dabholkar, P. A. \& Bogazzi, R. (2002). An attitudinal model of technology-based self-service: Moderating effect of consumer traits and situational factors. Journal of Academy of Marketing Science, 30(3), 184-202.

Dasgupta, S., Granger, M. \& McGarry, N. (2002). User acceptance of e-collaboration technology: An extension of technology acceptance model. Group Decisions and Negotiations, 11, 87-100.

Davis, F., Bagozzi, R. P. \& Warshaw, P. R. (1989). User acceptance of computer technology: A comparison of two theoretical models. Management Science, 38(8), 982-1003.

Deci, E. L. (1975). Intrinsic motivation. New York: Plenum Press.

Deng, X., Doll, W. J. \& Truong, D. (2004). Computer self-efficacy in an ongoing use context. Behaviour E Information Technology, 23(6), 395-412.

Dishaw, M. T., Strong, D. M. \& Bandy, D. B. (2002). Extending the task-technology fit model with self-efficacy constructs. In Human-Computer Interaction Studies in MIS. Eighth Americas Conference on Information Systems. [viewed 1 Mar 2009, verified 29 Mar 2010] http: / / sigs.aisnet.org/SIGHCI/amcis02_minitrack/RIP/Dishaw.pdf

Ellen, P. S., Bearden, W. \& Sharma, S. (1991). Resistance for technological innovations: An examination of the role of self-efficacy and performance satisfaction. Journal of Academy of Marketing Science, 19(4), 297-307.

Gefen, D. \& Straub, D. (2000). The relative importance of perceived ease-of-use in IS adoption: A study of e-commerce adoption. Journal of the Association for Information Systems, 1(8), 1-28.

Goodhue, D. L. \& Thompson, R. L. (1995). Task technology fit and individual performance. MIS Quarterly, 19(2), 213-236.

Hall, G.E. (1979). The concerns-based approach to facilitating change. Educational Horizons, 57, 202-208.

Hong, W., Wong, J. Y. L. \& Tam, K. Y. (2002). Determinants of user acceptance of digital libraries: An empirical examination of individual differences and system characteristics. Journal of MIS, 18, 97-124.

Hu, P., Clark, T. \& Ma, W. (2003). Examining technology acceptance teachers: A longitudinal study. Information \& Management, 41, 227-249.

Igbaria, M. \& Iivari, J. (1995). The effects of self-efficacy on computer usage. Omega, 23, 587-605. 
Kennedy, G., Dalgarno, B., Bennett, S., Judd, T., Gray, K. \& Chang, R. (2008). Immigrants and natives: Investigating differences between staff and students' use of technology. In Hello! Where are you in the landscape of educational technology? Proceedings ascilite Melbourne 2008. http:// www.ascilite.org.au/conferences/melbourne08/procs/kennedy.pdf

Kimmel, E. \& Killbride, M. P. (1991). Attribution training for teachers. Unpublished Research Report. [ERIC Reproduction Service No ED335345].

Kwon, O., Choi, K., \& Kim, M. (2007). User acceptance of context-aware services: Self-efficacy, user innovativeness and perceived sensitivity on contextual pressure. Behavior $\mathcal{E}$ Information Technology, 26(6), 483-498.

Lowry, G. (2002). Modeling user acceptance of building management systems. Automation in Construction, 11(6), 695-705.

Ma, Q. \& Liu, L. (2004). Technology acceptance model: A meta-analysis of empirical findings. Journal of Organizational End User Computing, 16, 59-72.

Mathieson, K. (1991). Predicting user intention: Comparing the TAM with the theory of planned behavior. Information System Research, 2, 173-191.

Ndubisi, N. O. (2006). Factors of online learning adoption: A comparative juxtaposition of the theory of planned behavior and the technology acceptance model. International Journal on Elearning, 5(4), 571-591.

Rogers, E. M. (2003). Diffusion of innovations. 5th ed. Free Press: New York.

Saade, R. G., Nebebe, F. \& Tan, W. (2007). Viability of the "technology acceptance model" in multimedia learning environments: A comparative study. Interdisciplinary Journal of Knowledge and Learning Objects, 3, 175-184. [verified 29 Mar 2010] http: / / www.ijello.org/Volume3/IJKLOv3p175-184Saade393.pdf

Sahari, M. (2001). Sense of efficacy among Malaysian secondary school teachers. Asia Pacific Journal of Education, 21, 66-74.

Sam, H. K., Othman, A. E. A. \& Nordin, Z. S. (2005). Computer self-efficacy, computer anxiety, and attitudes toward the Internet: A study among undergraduates in Unimas. Educational Technology E Society, 8(4), 205-219. http: / / www.ifets.info/journals/8_4/19.pdf

Schepers, J. \& Wetzels, M. (2007). A meta-analysis of technology acceptance model: Investigating subjective norm and moderation effect. Information \& Management, 44, 90-103.

Selwyn, N. (2006). The use of computer technology in university teaching and learning: A critical perspective. Journal of Computer Assisted Learning, 23, 83-94.

Shih, H. P. (2004). An empirical study on predicting user acceptance of e-shopping on the web. Information \& Management, 41, 351-369.

Salomon, G. (1984). Television is "easy" and print is "tough": The differential investment of mental effort in learning as a function of perceptions and attributions. Journal of Educational Psychology, 76, 647-658.

Straub, D. W., Keil, M. \& Brenner, W. (1997). Testing the technology acceptance model across cultures: A three country study. Information \& Management, 33, 1-11.

Straub, E. T. (2009). Understanding technology adoption: Theory and future directions for informal learning. Review of Educational Research, 79(2), 625-649. 
Teo, T. (2008). Pre-service teachers' attitudes towards computer use: A Singapore survey. Australasian Journal of Educational Technology, 24(4), 413-424.

http:/ / www.ascilite.org.au/ajet/ajet24/teo.html

Venkatesh, V. \& Davis, F. (2000). A theoretical extension of the technology acceptance model: Four longitudinal field studies. Management Science, 46, 186-204.

Venkatesh, V., Morris, M. G., Davis, G. B. \& Davis, F. D. (2003). User acceptance of information technology: Towards a unified view. MIS Quarterly, 37(3), 425-478.

Yi, M. Y. \& Hwang, Y. (2003). Predicting the use of web-based information system: Self-efficacy, enjoyment learning goal orientation, and the technology acceptance model. International Journal of H-C Studies, 59, 431-449.

Yousafzai, S. Y., Foxall, G. R. \& Pallister, J. G. (2007). Technology acceptance: A meta-analysis of the TAM (Part 1). Journal of Modeling in Management, 2(3), 251-280.

Assistant Professor Dr Tunku Badariah Tunku Ahmad

Associate Professor Dr Kamal Basha Madarsha

Associate Professor Dr Ahmad Marzuki Haji Zainuddin

Associate Professor Dr Nik Ahmad Hisham Ismail

Professor Dr Mohamad Sahari Nordin

Institute of Education, International Islamic University Malaysia, Kuala Lumpur

Email: tbadariah@iiu.edu.my, kamalbasha@iiu.edu.my,marzuki@iiu.edu.my,

nikahmad@iiu.edu.my,msahari@iiu.edu.my

Web: http: / / www.iiu.edu.my/educ/

Please cite as: Ahmad, T. B. T., Basha, K. M., Marzuki, A. M., Hisham, N. A. \& Sahari, M. (2010). Faculty's acceptance of computer based technology: Cross-validation of an extended model. Australasian Journal of Educational Technology, 26(2), 268-279. http:/ / www.ascilite.org.au/ajet/ajet26/ahmad.html 